\title{
The Flip Side Of The Coin: An Organizational Scan Of Domestic Student Attitudes Towards Their International Counterparts
}

\author{
Deniss Yeung, (E-mail: Deniss.Yeung@wintec.ac.nz), Wintec University, New Zealand
} Ted Dunlop, (E-mail: Ted.Dunlop@wintec.ac.nz), Wintec University, New Zealand

\begin{abstract}
This study was prompted by one institution's decision to make Internationalization a strategic priority. Through ongoing internal surveys of International students, it has been possible to gauge their impressions, attitudes and areas of concern. However, on quick review of the literature, it became apparent that there is a dearth of research on how Domestic students view their International counterparts. The researchers set out to redress this imbalance and from the insights gained put forward recommendations to strengthen social interaction; influence teaching practice and embed an Internationalization dimension into programme curricula. The findings paint an optimistic picture for improving the learning experience for all students through planned and well thought out interventions.
\end{abstract}

\section{INTRODUCTION}

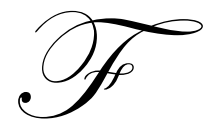

or some time, post-secondary/tertiary institutions in Western countries have been reaping the benefits of a large influx of students from so-called 'developing' countries. This global migration of students has been happening for some time but picked up momentum in the 1980s for countries like the United States, Australia, Canada and more recently, New Zealand in the past five years in particular. Very early on, it became apparent that International students provided a convenient and rather lucrative revenue stream - especially for public institutions feeling the pinch of shrinking government funding over time. Agents were hired to trawl for students and outposts were established by the bigger players over time in order to establish a physical presence in the feeder countries. Recruitment fairs have become part of the landscape and universities and colleges have established internal International arms to attract their fair share of the market. Chief executives have travelled the world to sign up new partners under the rubric of memoranda of understanding. Commitments have been made to exchanges which have happened to varying degrees. However, the traffic until recently has been largely one way, with students leaving their home countries for popular destinations in the United States, Canada, Australia and the United Kingdom.

In recent years, more attention has been given to building quality into the experiences for International students. In too many cases, this has been the result of horror stories as students return to their home countries with accounts of poor service and support, strong feelings of alienation from the host country; and provision of few opportunities for integration with Domestic students and, in some cases, personal experience with racism and hostility. In a small country like New Zealand, bad press and the recent closure of a spate of private language schools has had a direct and marked impact on the numbers of International students identifying New Zealand as their country of choice for study abroad. Also, changing government policy in some of the feeder countries has placed more emphasis on building the internal infrastructure in higher education as a way of staunching the brain drain of talented young people out of the country who may then choose not to return. 
In order to protect their investment hosting International students, tertiary institutions in Western countries have made a concerted effort in recent years to strengthen pastoral support for International students by introducing a range of supporting services to enhance the experience of these students. A good example of this can be found with the Code of Practice for the Pastoral Care of International Students that was instituted by the New Zealand Ministry of Education on 31 March 2002 and revised in July 2003. As an aside, it is interesting to note that this particular code makes no reference to the importance of developing strategies for integration of International students with Domestic students in our various institutions. As experience shows, simply placing students in close proximity does not, by itself, guarantee that bonds of affiliation and connectedness will naturally ensue. And yet, institutions have come to realize that building a loyal alumni base among foreign students who feel well connected to the host institution can also well serve the interests of the institution and host country over the long-term. More importantly, many of these same institutions are shifting attention to the non-monetary reciprocal benefits that can be accrued from the presence of significant numbers of International students on their campuses. Hence, a growing emphasis is being placed on Internationalization as a process for fostering greater interaction and understanding among increasingly diverse student populations. At the same time in some jurisdictions, it is being seen as a potent antidote to the hostility and racism that has flared up on some campuses and spawned the emergence of fringe campus groups committed to resisting the tide of foreign student influence on institutional policy, decision-making and allocation of finite resources. Another positive outcome of this new emphasis on Internationalization is growing recognition of the need to equip Domestic students with a level of 'cultural intelligence' that will better prepare them for living and working in the global economy. In her survey of Canadian universities, Knight (2000) found that "increased employability and access to more job opportunities in a global marketplace" ranked very highly as a prime benefit of Internationalization (p. 21).

The purpose of this study is to penetrate the thinking of our own Domestic students here at Waikato Institute of Technology to better understand their attitudes and perceptions of International students and, hopefully, gain from them a clearer sense of the kind of strategies that will enhance mutual understanding, trust and more meaningful social interaction. It is an attempt, as Segal (1994) put it, to conduct a study that "illuminates the way students think, by shining a floodlight into the dark recesses" (p. 17). At the same time, it is intended to redress the paucity of research on Domestic student perspectives on Internationalization as noted by Ward (2001) among others. For purposes of this study, International students are defined as full foreign fee paying students present in New Zealand on student visas. Our focus is on these students rather than permanent residents and refugees/new migrants but acknowledging at the same time that Domestic students are not likely to recognize such distinctions. Also, the definition of Internationalization we are using is taken from Knight (2003) who has defined the concept as "the process of integrating an International, intercultural, global dimension into the purpose, functions and delivery of higher education" (p. 2). We are hoping as well that our findings can be extrapolated to have some relevance for other tertiary institutions, not only here in New Zealand but also in other 'Western' countries. It is also a plea for university and college planners to take a more balanced perspective in designing services that foster integration and better appreciation of the reciprocal benefits to be accrued by having International students on campus. Such thinking also needs to permeate the curricula of our programmes with the leadership coming from faculty in order to make this happen.

Knight (1997) has put forward four categories for clustering the benefits to be gained from Internationalization: "political, academic, economic and cultural/social" (p. 9). Under these broad headings, it is possible to make some clear assumptions about the benefits that Domestic students are expected to gain from contact with International students - assumptions about greater respect for cultural diversity; a better understanding of different worldviews; greater tolerance of differences; heightened adaptability; more effective communication skills; sharpened critical thinking skills; development of a more global outlook and greater opportunity for networking and relationship building for future professional and commercial gain. These are admirable and lofty goals to aspire to. We might pay lip service to these benefits but there is little hard evidence to suggest to date that our Domestic students, in particular, have bought into these advantages through close physical proximity with their International peers. The reality on the ground may paint a very different picture of student attitudes towards their foreign counterparts. In this study the authors attempt to mine the attitudes of Domestic students about International students, the challenges as they see them and the opportunities for promoting better interaction and understanding as well as suggestions for improving institutional policies and practices. 
The institutional gains of Internationalization are relatively easy to gauge, as noted earlier. However, once we get down to the level of the student, the picture becomes murky. International students come to our shores expecting and desiring interaction and contact with their Domestic counterparts. However, anecdotal evidence, backed up by research, suggests that meaningful social interaction is quite low and the bonds very weak, to say the least. Domestic students are portrayed as somewhat apathetic and disinterested in developing meaningful relationships with International peers. As a result, perceptions arise about the clannishness of International students; their propensity to work too hard and achieve better results than their Domestic peers. As well, there is evidence that Domestic students believe that International students expect more help from teachers than they actually do (Ward, 2004, p. 15). To add fuel to the fire, some faculty members will argue that International students - and especially those for whom English is their second language - impose an unreasonable burden in the classroom. Although outside of the scope for this particular study, there is an urgent need for more evidence-based research to examine what it will take to change the content and processes of educational activities in the classroom. To date, there is little evidence to suggest that educators are making serious efforts at accommodating the International student perspective in their teaching practice and design of curricula (Ward, 2004, p. 3). From this study, we expect to be able to corroborate many of these findings, add new insights gained from the research and put forward interventionist strategies that will focus on the classroom experience and the range of supporting services wrapped around our courses and programmes.

\section{BACKGROUND}

Waikato Institute of Technology, more popularly known as Wintec, is the fifth largest institute of technology/polytechnic in New Zealand. Founded in 1924 as the Hamilton Technical College, the institution has evolved over time from its original mandate to deliver largely technical and trades training in the Waikato region, to become a more comprehensive institution offering courses and programmes at certificate, diploma, baccalaureate and postgraduate levels that now serve local, regional, national and International markets. Throughout its history, however, Wintec has held true to its commitment as a leading provider in New Zealand of applied, vocational and professional education.

As of June 2005, the total percentage of International students enrolled at Wintec stood at $13.9 \%$ with the majority coming from China (67\%) followed by India (10\%) with the remainder drawn from other countries. In the past two years, a major strategic commitment has been made to 'internationalize' the organization in keeping with Knight's (2003) definition of Internationalization referred to earlier. This goal has been enshrined in the Strategic Profile for the Institute as stated in Wintec's mission, vision, values and goals (2005) with a clear intent to:

Improve the educational, research, cultural and financial resource base of Wintec by increasing the number and diversity of International students; enhancing International perspectives in courses; providing additional collaborative research and exchange opportunities with overseas institutions; introducing new self-funding and institute-wide activities that broaden international experiences for all parties and maintain on-going contact with International students; support the professional development of our staff and better prepare our New Zealand students for living and working in a globalized economy.

A key aspect of this strategy is to better equip New Zealand students with clear knowledge and understanding of global perspectives through their experiences inside and outside of the classroom. A number of strategies are being proposed to meet this end from student exchanges, visiting International scholars, offering of programmes overseas, peer mentoring schemes, multicultural festivals and events, inclusion of International examples and perspectives within courses and programmes, student study tours overseas, professional development opportunities for staff to enhance their understanding of global perspectives, scholarship schemes for Domestic students studying abroad and creation of a physical environment that reflects a strong interest and commitment to Internationalization.

Through this study, it is our hope to gauge the attitudes of Domestic students towards their International counterparts, examine what benefits (if any) they feel are to be derived from a process of Internationalization and finally to identify concrete strategies, in addition to the ones already outlined, that can enhance the quality of interactions between Domestic and International students and promote better understanding, trust and more meaningful social interaction. 


\section{METHODOLOGY}

This study utilised primarily quantitative and qualitative methods to explore the impact of International students on Domestic students. A web survey was developed and emailed to all enrolled Domestic students with an email address at Waikato Institute of Technology. Survey participants were asked to evaluate various aspects of their cross-cultural experience with International students, to answer questions on the impact of International students on their educational experience, and to provide some basic demographic information.

\section{Pilot Studies}

To ensure the reliability and validity of the research instrument, a pilot study was conducted. The study consisted of four staff members - two were from the arm providing ICT technical support across the Institute and two were from the School of Communication. These four individuals reviewed the questionnaire and tried out the online survey. The feedback of the staff was used to modify technical aspects of the survey administration and the content of the questionnaire, as appropriate.

\section{Survey Questionnaire}

The survey instrument was a self-administered, multidimensional, Likert-scale questionnaire (Table 1). The questionnaire included both open-ended response questions and close-ended (fixed-alternative) questions. Open-ended questions posed a hypothetical problem and asked each respondent to answer in his/her own words. For close-ended questions, respondents were given specific, limited-alternative responses and asked to choose the one closest to their own individual viewpoint. A Likert-scale, dropdown manual as well as 'Yes'/'No' options were used in close-ended questions to generate interest and keep respondents focused.

There were 53 items all together: 1 on educational experience; 3 on cross-cultural sensitivity; 4 on crosscultural competence; 4 on academic environment; 4 on International interest; 14 on cross-cultural interactions with International students; 4 on interest in cross-cultural interaction; 9 on perception of International students; 4 on perceived teaching staff ability and 6 on demographic characteristics.

The first part of the questionnaire (Questions 1 to 3) was made up of easy questions as a warm-up for respondents and to allow them to build confidence. The middle part of the questionnaire (Questions 4 to 18) demanded more thinking and at the end of the questionnaire (Questions 19 to 24), more personal information was solicited.

Table 1: Survey Questions Corresponding To Research Aspects

\begin{tabular}{|lll|}
\hline Aspect & & Survey Question \\
\hline 1. Educational experience & Q 5. & $\begin{array}{l}\text { To what extent do you agree or disagree with this statement: "Intercultural } \\
\text { experiences with International students are important to my personal and } \\
\text { professional development." }\end{array}$ \\
& & \\
\hline $\begin{array}{l}\text { 2. Cross-cultural interactions } \\
\text { with International Students }\end{array}$ & Q 1a. & Have you taken any ethnic studies courses? \\
& Q 1b. & Have you travelled outside of New Zealand? \\
& Q 1d. & Have you lived outside of New Zealand? \\
& Q 2a. & Have you studied abroad? \\
& Q 2b. & Have you participated in small discussion groups with International students? \\
& Q 2c. & Have you worked on group projects with International students? \\
& Q 2d. & Have you had a peer tutor who was an International student? \\
Q 2e. & Have you talked with an International student outside of class? \\
Q 2f. & Have you worked with International students on a job? \\
Q 3. & How would you rate your frequency of interaction with International students? \\
& & \\
\hline
\end{tabular}




\begin{tabular}{|c|c|c|}
\hline & $\begin{array}{l}\text { Q } 4 . \\
\text { Q } 6 . \\
\text { Q } 7 . \\
\text { Q } 8 . \\
\text { Q } 9 . \\
\text { Q } 10 . \\
\text { Q } 18 .\end{array}$ & $\begin{array}{l}\text { How easy or difficult is it for you to make the distinction between International } \\
\text { students, permanent residents and refugees from visible minorities? } \\
\text { After you graduate, would you be interested in working with people from other } \\
\text { countries? } \\
\text { How comfortable are you interacting with International students at Wintec? } \\
\text { How many friends have you made on campus who are International students? } \\
\text { Level of interest in establishing friendships with International students. } \\
\text { Interested in participating in Wintec programs/events that encourage you to interact } \\
\text { with International students. } \\
\text { How would you rate your overall experience with International students? }\end{array}$ \\
\hline 3. Cross-cultural competence & $\begin{array}{l}\text { Q } 13 a . \\
\text { Q } 13 b . \\
\text { Q } 13 c . \\
\text { Q } 13 d .\end{array}$ & $\begin{array}{l}\text { Your ability to work in another country after you graduate. } \\
\text { Your ability to communicate with people of different cultures. } \\
\text { Your knowledge of global problems and issues. } \\
\text { Your awareness of the heritage and history of other cultures. }\end{array}$ \\
\hline 4. Academic environment & $\begin{array}{l}\text { Q 11a. } \\
\text { Q 12a. } \\
\text { Q 14c. } \\
\text { Q 14f. }\end{array}$ & $\begin{array}{l}\text { International students on campus have inspired me to study harder. } \\
\text { International students on campus have brought different knowledge, skills, and } \\
\text { ideas to my classes. } \\
\text { International students enhance the intellectual atmosphere on campus. } \\
\text { International students add cultural diversity to the campus environment. }\end{array}$ \\
\hline 5. International interest & $\begin{array}{l}\text { Q } 11 b . \\
\text { Q } 11 c . \\
\text { Q } 11 d . \\
\text { Q } 17 .\end{array}$ & $\begin{array}{l}\text { International students on campus have interested me in studying abroad. } \\
\text { International students on campus have interested me in learning foreign languages. } \\
\text { International students on campus have inspired me to pursue a career in another } \\
\text { country. } \\
\text { What do you expect you will get from International students? }\end{array}$ \\
\hline 6. Cross-cultural sensitivity & $\begin{array}{l}\text { Q } 12 b . \\
\text { Q } 12 c . \\
\text { Q } 12 d .\end{array}$ & $\begin{array}{l}\text { International students on campus have helped me learn to accept other points of } \\
\text { view. } \\
\text { International students on campus have helped me to appreciate other cultures. } \\
\text { International students on campus have made me more aware to my own cultural } \\
\text { background and values. }\end{array}$ \\
\hline $\begin{array}{l}\text { 7. Perception of } \\
\text { International students }\end{array}$ & $\begin{array}{l}\text { Q } 14 a . \\
\text { Q } 14 \mathrm{~b} . \\
\text { Q } 14 \mathrm{~d} . \\
\text { Q } 14 \mathrm{e} . \\
\text { Q } 14 \mathrm{~g} . \\
\text { Q } 14 \mathrm{~h} . \\
\text { Q } 14 \mathrm{i} . \\
\text { Q } 14 \mathrm{j} . \\
\text { Q } 14 \mathrm{k} .\end{array}$ & $\begin{array}{l}\text { International students are usually highly motivated and do well in their courses. } \\
\text { International students' English is hard to understand. } \\
\text { International students tend to stay in their own communities. } \\
\text { International students usually interact with New Zealanders for their own social or } \\
\text { academic benefit. } \\
\text { International students should adapt to our culture since they are in our country. } \\
\text { International students pose a physical threat to New Zealanders. } \\
\text { I feel comfortable in assisting international students on course group work. } \\
\text { High numbers of international students have affected my studies in a negative way. } \\
\text { International students consume too much class time. }\end{array}$ \\
\hline 8. Teaching staff's ability & $\begin{array}{l}\text { Q } 15 a . \\
\text { Q } 15 b . \\
\text { Q } 15 c . \\
\text { Q } 16 .\end{array}$ & $\begin{array}{l}\text { Teaching staff's ability to allocate sufficient time for both domestic and } \\
\text { international students. } \\
\text { Teaching staff's ability to handle different cultures in classes. } \\
\text { Teaching staff's ability to handle high numbers of international students in classes. } \\
\text { What do you expect from teaching staff in classes with many international students? }\end{array}$ \\
\hline $\begin{array}{l}\text { 9. Demographic traits of } \\
\text { surveyed Domestic students }\end{array}$ & $\begin{array}{l}\text { Q } 19 . \\
\text { Q } 20 . \\
\text { Q } 21 \\
\text { Q } 22 . \\
\text { Q } 23 . \\
\text { Q } 24\end{array}$ & $\begin{array}{l}\text { What level of study are you currently working toward? } \\
\text { What year are you in your studies? } \\
\text { What is your major school at Wintec? } \\
\text { What is your age? } \\
\text { What is your gender? } \\
\text { What is your ethnicity? }\end{array}$ \\
\hline
\end{tabular}




\section{Data Collection Procedures}

Initially, more than 4000 domestic email addresses were identified but it was found that the term 'school' appeared in some of the email addresses. After discussion with Information Services personnel, it was noted that a good number of those email addresses were either secondary students who were doing Wintec's STAR (Secondary Tertiary Alignment Resource) programme aimed at secondary school students or students doing tertiary level courses online. Since these students did not fulfill the research criteria, the email addresses were then eliminated. A revised list of email addresses was produced and the number was reduced from over 4,000 to under 2,000.

The following criteria were used to identify the sample for this study:

1. Must be enrolled in a 2005 class covering one or more months of March, April or May.

2. 'Class is online' is set to 'No'. (The student must be enrolled in a class with International students).

3. 'Module Internet category' is set to 'Not Web enabled'.

4. Student Citizenship is not 'International'. (Student must be New Zealand citizen or permanent resident)

5. Class location is identified by campus.

6. Enrolment type is 'Domestic' (Ministry of Education funded).

Data collection commenced on 4 May, 2005. E-mail messages were sent to 1853 Domestic students and New Zealand permanent residents at Wintec with an email address. The messages were sent in three separate batches to prevent the web server from being overloaded with too many requests at one time. In order to increase the number of respondents the questionnaire was sent again on 18 May, 2005 (two weeks after the first round). Every student received a standard e-mail message briefly explaining the purpose of the study and requesting his/her participation. As an incentive, students who completed surveys were entered into a draw for one of two book vouchers worth $\$ 50.00$.

For the web questionnaire, a linear construction format was used (Table 2).Respondents were asked to answer each of the questions, but were permitted to skip questions if they wished. The survey application was written in XHTML (Dreamweaver), and extensive usability was conducted to ensure consistent behaviour over a different range of computing platforms (meaning that respondents who use Apple or old technology were still able to view and do the survey).

Survey responses remained strictly anonymous to the researchers by having an independent administrator process the emails and arrange the draw for a $\$ 50.00$ book voucher under a confidentiality agreement. Those respondents who chose not to enter the draw did not supply an email address; therefore their details would not be identified.

The rationales for a web-based survey were threefold:

1. Efficiency: by contacting the participants via e-mail and administering the survey via the web, survey costs (e.g., paper, postage, mail-out, and data entry) were reduced considerably. Had the survey been administered through the mail, printing and postage alone would have been prohibitive.

2. Access: about 52\% of Domestic students enrolled at Wintec have access to the internet. Thus a web survey provided a readily available sample and limited the possibility of coverage errors.

3. Accuracy: the consistency of the presentation and the administration of the questionnaire reduced random variability. In addition, data entry errors were avoided.

\section{Data Return And Analysis Procedures}

Of the 1853 surveys distributed to Domestic students, 261 were completed, for a response rate of $14 \%$. Six responses were discarded due to undefined, garbled or duplicated replies (these were nonsense and incomplete replies). 
Upon completion of the data collection, the survey responses were imported into Microsoft Excel for analysis. The analysis consisted of two stages:

1. Computation of summary statistics including totals and percentages for each of the quantitative survey questions.

2. Qualitative analysis of written comments. A qualitative analysis was conducted on the large number of written comments provided by the survey respondents.

\section{Findings}

The present study set out to redress the paucity of research conducted to date looking into the attitudes, perceptions and feelings of Domestic students towards their International counterparts. From the insights gained from canvassing 255 of our students, it is hoped that a contribution can be made to better understanding the perspective of Domestic students at an institutional level and use these findings as a catalyst for strengthening a strategic commitment that has been made to advancing the cause of Internationalization. Before conducting this study, the authors expected that both segments of our present student population co-exist in parallel worlds with little opportunity for truly meaningful interaction. The findings confirm some of our hunches and dispel others. Yet, it is our contention, that there is room for considerable improvement in the way Domestic students perceive their International peers and the reciprocal benefits to be accrued from more meaningful contact across the divide that currently exists. From the analysis of our findings, a number of key features have emerged that are worth highlighting. To begin, it is worth noting some of the key characteristics of the participants in the study: $68 \%$ identify as New Zealand European/Pakeha; 3\% Chinese; 10\% New Zealand Maori; 4\% other Asian ethnic groups; $1 \%$ Indian, Cook Island Maori and Tongan and the balance labelled themselves as "other" at $14 \%$. The bulk of the participants in the study are studying at bachelor's level (slightly over 52\%) with $29 \%$ at diploma level; $13 \%$ at certificate level and $2-3 \%$ at postgraduate level. The balance did not indicate a specific level of study. The greatest number of participants indicated that they were in their first year of study (approximately 42\%) with nearly $24 \%$ in second year; $16 \%$ in third year; $12 \%$ in fourth year and the remainder in fifth and sixth years of study. Nearly $66 \%$ of respondents were women. The largest segment of the total number surveyed fell in the 15-24 age bracket (43\%) followed by $24 \%$ between 35 $44 ; 19 \%$ between 25 and 34; $8 \%$ at 45 to 54;3\% between 55 and 64 and approximately $1 \%$ at 65 or older.

From this profile, we were able to glean a significant amount of information that will greatly support our efforts at an institutional level to put in place specific strategies for strengthening interaction between Domestic and International students. Outlined below are the important findings that will help us chart that course for the future.

\section{RESULTS}

- $\quad$ To begin on a positive note, a significant number of our students rated their overall experience with International students as good or very good (51\% and $11 \%$, respectively). Only a small percentage totally $13 \%$ rated their experience as poor or very poor.

- Only a small number of those surveyed had participated in any formal courses in cross-cultural studies $(12 \%)$.

- Interestingly, a significant number (82\%) had travelled outside of New Zealand.

- $\quad$ A high number had actually lived outside New Zealand (49\%).

- A significant number have studied abroad (23\%).

- When asked about participation in campus events or activities with International students, the majority (69\%) reported that they had not engaged in activities with International students.

- $\quad$ Roughly, 57\% had participated in small group discussions with International students in a classroom context.

- $\quad$ Almost an equal number (50\%) had worked with International students on group projects.

- $\quad$ Very few Domestic students had the support of a peer tutor who was an International student (7\%).

- A significant number (74\%) reported that they had engaged in casual conversation with International students outside of the classroom.

- Interestingly, 27\% reported that they had worked with International students in the workplace. However, $71 \%$ did not have exposure to International students in a job context. 
- $60 \%$ of respondents rated their frequency of interaction with International students as low or very low. Seven percent indicated no contact whatsoever and the remaining number reporting high or very high contact $(33 \%)$.

- When asked how difficult it was to categorize International students, permanent residents and refugees from visible minorities, $32 \%$ indicated that they didn't know. Forty percent found it difficult or very difficult and the balance reported that it was easy or very easy to make the distinctions.

- On the question of the value of intercultural experiences with International students, $44 \%$ agreed with the question with another $15 \%$ strongly agreeing. Twenty-eight percent could not agree or disagree. A small percentage of $11 \%$ indicated that they disagreed or strongly disagreed.

- $\quad 42 \%$ and another $20 \%$ indicated that they would be interested and very interested in working with people from other countries with $32 \%$ remaining neutral and a small figure who expressed disinterest.

- When asked to rate how comfortable they were interacting with International students, a significant number reported that they were comfortable or very comfortable with their interactions with International students (44\% and $21 \%$, respectively). A further $24 \%$ were neutral and a small fraction (10\%) reported that they were uncomfortable or very uncomfortable in their interactions with International students.

- When asked to give the number of friends they had made on campus, 38\% reported 0 with another $38 \%$ listing 1-3 but a surprising number $4-10(17 \%)$ and $7 \% 10$ or more.

- $\quad$ Only a small number (4\%) indicated that they were disinterested or very disinterested in forming friendships with International students. Fifty-two percent were neutral with $34 \%$ interested and the remainder very interested (9\%).

- When asked to comment on level of interest in participating in Wintec programmes/events that encourage interaction with International students, $42 \%$ took a neutral stance with another 16\% disinterested. 36\% expressed an interest or strong interest in participating in such events. Only a small fraction failed to indicate any preference.

- $\quad$ Although $46 \%$ of respondents could neither agree or disagree on whether or not having International students on campus, inspired them to work harder, more disagreed or disagreed strongly (37\%). The remaining number either agreed or strongly agreed.

- On the point of International students stimulating an interest in studying abroad, $43 \%$ could not agree or disagree. Seventeen percent and $21 \%$, respectively, recorded "strongly disagreed" or "somewhat disagreed" as their choices. Another $19 \%$ somewhat agreed or strongly agreed.

- A significant number (34\%) indicated that having International students on campus piqued their interest in learning a foreign language with a further $9 \%$ indicating strong agreement. The remainder disagreed or didn't have a preference in any direction.

- On the prospect of influencing a choice to work in another country, the largest proportion of respondents remained neutral $(40 \%, 16 \%$ and $19 \%$, respectively, recorded "strongly disagreed" or "somewhat disagreed" as their choices. Another $23 \%$ somewhat agreed or strongly agreed.

- Forty-one percent of respondents agreed when asked if International students brought different knowledge, skills and ideas to their classes with a further $14 \%$ strongly agreeing. A significant number (27\%) couldn't agree or not agree. The remaining $18 \%$ disagreed to varying degrees.

- On the question of International students helping their Domestic classmates learn to accept other points of view, $36 \%$ agreed somewhat; $18 \%$ strongly agreed. Thirty percent didn't have an opinion to offer and with the remainder disagreeing or strongly disagreeing.

- Gaining appreciation of other cultures was noted by the majority of respondents (approximately 68\%) with $20 \%$ remaining neutral and the remaining portion of the sample disagreeing or strongly disagreeing.

- Heightened appreciation of one's own culture was noted by $55 \%$ of the respondents. A further $30 \%$ didn't proffer an opinion and the remaining $15 \%$ disagreed or strongly disagreed.

- A significant majority rated their ability to work in another country following graduation as good (49\%) or excellent $(20 \%)$. Only a small fraction (5\%) ranked their ability as poor while the remaining students gave their chances as fair.

- Basically, similar figures applied when asked to rate their ability to communicate with people of different cultures. 
- $\quad$ For assessment of knowledge of global problems and issues, again a significant majority ranked their levels as good (44\%) or excellent (9\%). Thirty-eight percent opted for a fair rating with only $9 \%$ ranking their level of knowledge as poor.

- In respect to awareness of the heritage and history of other cultures, $46 \%$ ranked themselves as having a fair awareness with $35 \%$ plus giving themselves a good rating and $7 \%$ an excellent rating. Twelve percent indicated a poor awareness of the heritage and history of other cultures.

- A significant number of those surveyed agreed or strongly agreed that International students were highly motivated and did well in their courses (55\%). Thirty-one percent didn't feel able to make a judgment and approximately $14 \%$ disagreed or strongly disagreed.

- In respect to English language proficiency a considerable majority (close to 73\%) agreed that it was difficult to understand the English of many International students. Twenty-one percent didn't espouse any particular position on this item and only a small number (6\%) disagreed.

- When asked to comment on whether or not International students enhanced the intellectual atmosphere on campus, 52\% stood neutral. Thirty-four percent agreed to varying degrees. Only $14 \%$ disagreed.

- It is commonly agreed that many International students tend to be ghettoized. This perception was reinforced by our findings. Most respondents agreed or strongly agreed. Fourteen percent remained neutral and $4 \%$ disagreed.

- Forty-four percent of respondents indicated that they couldn't make a judgment one way or the other on whether International students make an effort to interact with New Zealanders for their own social or academic benefit. Close to $32 \%$ thought they did but another $24 \%$ didn't agree.

- It was easier for a significant number of New Zealand students to agree that International students added to the cultural diversity of the campus environment (74\%). Twenty percent sat on the fence on this item with only $6 \%$ disagreeing.

- On the thorny question of whether or not International students should adapt to our Kiwi culture while in the country, 29\% remained neutral. However, $31 \%$ disagreed on this point.

- $\quad$ For the interesting question of whether or not International students posed a physical threat to New Zealanders, the overwhelming majority said no $(68 \%)$ with over $22 \%$ remaining neutral and the remaining $8 \%$ agreeing somewhat or strong.

- When asked how comfortable they were in assisting International students on course group work, 63\% indicated that they were somewhat or very comfortable helping their International counterparts. Twenty-six percent remained neutral with the remaining $11 \%$ expressing that they weren't comfortable providing this kind of assistance.

- An overwhelming majority of respondents (65\%) did not feel that the high numbers of International students affected their studies in a negative way.

- A closely aligned question was posed about the amount of class time International students consumed. A near majority $(48 \%)$ did not feel that International students consumed too much class time. Thirty-three percent remained neutral but $19 \%$ did feel that International students were consuming too much class time.

- A majority of students (58\%) rated the teaching staff's ability to allocate sufficient time for both Domestic and International students as good to excellent. Thirty-two percent rated this item as fair and $7 \%$ as poor. Three percent didn't rate the item.

- On the ability to handle different cultures in a class context, teaching staff in general were rated quite highly with $49 \%$ noted as good; another $14 \%$ as excellent; $30 \%$ as fair and $4 \%$ as poor. A small number (3\%) did not rate this item.

- When asked to rate the ability of teaching staff to manage large numbers of International students in their classes, an overwhelming majority (84\%) rated their lecturers in the fair, good to excellent categories. Twelve percent gave a poor rating for this item and only $3 \%$ chose not to respond.

follows:

Two questions on the survey were open ended with the students encouraged to add their comments as 


\section{Q.16 Domestic Students' Expectations Of Teaching Staff In Classes With A Significant Number Of} International Students

- $\quad$ Pay equal attention to all students; apply same expectations to all students and spend equal amounts of time with both Domestic and International students.

- Assist International students who are weak in English before they join mainstream programmes or offer such support outside the classroom.

- $\quad$ Provide lecturers who have large number of International students with extra time or teaching assistants.

- $\quad$ Encourage International students to participate more and to share more in class.

- Use simple language, more examples, repeat keys points and speak slowly in class.

- Use students' names in class.

\section{Cultural awareness}

- $\quad$ Be aware of cultural differences \& learning styles.

- Be open-minded.

- $\quad$ Show respect, patience and tolerance.

- $\quad$ Be considerate and have tolerance for International students.

- $\quad$ Treat everyone as a student, not a nationality.

- Treat all cultures with respect and not discriminate against due to appearance or accent.

\section{Q.17 Expectations Of Domestic Students In Terms Of What They Will Gain From International Students}

- $\quad$ A different worldview and opinions of issues in New Zealand.

- Insight into new cultures and new ideas. Gaining new friends.

- $\quad$ Mutual friendship and help.

- $\quad$ Another person with whom to share perspectives / experiences / learning / achievements / disappointments and ways to overcome.

- Also an insight into other cultures, but this doesn't really happen unless you have regular contact outside of the campus and I have only had that sort of contact with one student who has now left the country.

- $\quad$ Push me to study hard.

- An understanding of different cultures and backgrounds. Also to learn how to communicate with people who have English as a second language.

- Insight into another culture and a different way of thinking. Cultural flavour. Experience and practice in communication skills and stretching to be able to explain things in other ways. Friends and contacts that will be lasting.

- I feel that having International students in class is a privilege as they provide different views on different topics as well as interact in class with different experiences that they have had in their home countries as well as other countries. Not only that, but we also gain a level of cultural understanding and are able to learn more about different cultures.

- $\quad$ I expect we will get some great professional trades people who will go on to work here in New Zealand, e.g., nurses.

- In my creative field, stories, views and experiences different from my own if I were to interact or work with them on projects.

\section{DISCUSSION AND RECOMMENDATIONS}

The findings of this study give cause for hope in strengthening opportunities for better communication and interaction between Domestic and International students on a number of different fronts and improve the learning experience for all students at the same time. As well, there is a clear call here for the development and modification of curriculum strategies to reflect different learning styles, some of which are culture based, and identification and collation of practice based teaching strategies that expedite a more integrated approach to learning for all students. 
For this to happen, the case must be made for a much more concerted and systematic approach to teacher development to support our academic staff in managing increasingly diverse cohorts of students.

From our findings, we can take heart that a significant number of students surveyed demonstrated more flexibility, openness and empathy in their attitudes and perceptions of their International counterparts than the researchers might have expected along with some recognition of the challenges that International students face in adjusting to a new language and culture. At the same time, our local students do seem to grasp the importance of acquiring a more global understanding of different cultures and worldviews with a view to expanding employment opportunities well beyond local, regional and national boundaries - a phenomenon abetted by the worldwide migration of labour that is accelerating and the impact that technology is exerting on the borderless transaction of business operations and decision-making. As well, there are a few other key factors at play that Knight (2004) adds to the list:

The escalating number of national, regional, international, and cultural conflicts is pushing academics to help students understand global issues and International/intercultural relationships. The mobility of the labour market and the increase in cultural diversity of communities and the workplace require that both students and academics have an increased understanding and demonstrated skills to work and live in a culturally diverse or different environment ( $p .26)$.

The challenge at the institutional level is to sell the reciprocal benefits to be gained from increased integration of Domestic and International students both inside and outside of the classroom. Much can be done to mitigate the clannishness exhibited on the part of many International students, usually brought about in reaction to the perceived indifference and apathy of their local classmates who, in all fairness, are oftentimes preoccupied balancing competing priorities in their own lives.

A significant number of participants in this study have noted the value and richness of intercultural experiences that International students bring with them, the strong work ethic they demonstrate and the motivating impact this can have on Domestic students. At the same time, this should not detract from the many challenges that remain around language proficiency, the social dynamics in the classroom that might, for example, impede group work and the skill of the teacher in mediating different communication and learning styles.

From this study, as already alluded to, there is also a clear acknowledgement of the importance of providing strong support to teaching staff and maintaining reasonable class sizes to ensure that equitable consideration is given to the needs of all students. Unfortunately, experience shows that too many teachers continue to hone their skills in working with mixed groups through trial and error. Much more is called for at the institutional level to support evidence based practice and curriculum design that is culturally responsive, reciprocal and flexible (Ho, Holmes and Cooper, 2004, p. 41) as well as promoting socialization strategies that strengthen interaction, celebrate differences and promote better understanding of cultural differences. Also, as Knight (2000) and others have pointed out, Internationalization can be integrated as one of the responses to the impact of globalization (p. 15) and institutions need to realize that "students are increasingly the focus for Internationalization efforts." (p. 90).

Changes in classroom dynamics must start, as Gay notes (Gay, 2000, cited in Ho et al., 2004) by acknowledging the complex set of variables that impact on the student experience as the following illustrates.

The absence of shared communication frames of reference, procedural protocols, rules of etiquette, and discourse systems makes it difficult for culturally diverse students and teachers to genuinely understand each other and for students to fully convey their intellectual abilities. Teachers who do not know or value these realities will not be able to fully access, facilitate, and assess most of what these students know and can do. Communication must be understood to be more than a linguistic system (Gay, 2000, in Ho et al., 2004, p. 28).

These suggestions point out the need for identification of very practical strategies that focus on the provision of well constructed professional development opportunities for teaching staff; smaller class sizes where high numbers of International students are concentrated; training in curriculum design to reflect International perspectives and 
incorporation of global examples to support learning outcomes; teaching secondments to other countries and participation in International consultancies. From the student perspective, the overarching goal should be to ensure that the learning needs of all students are being met and not compromised and the benefits of Internationalization are being clearly evidenced through effective classroom management. There are also well documented strategies such as student exchanges to ensure that the traffic flow isn't one way; International work placements supported by a strong internal career services arm; participation of students in hosting International delegations through promotion of a student ambassador programme; peer mentoring or buddy schemes to expedite the integration of new International students and workshops facilitated by International students that introduce the Domestic student audience to the history, culture, norms, values and aspects of business etiquette . As a brief aside, one programme noted by Ho et al., (2004, p. 57) that holds particular promise is the Excellence in Cultural Experiential Learning and Leadership Programme (ExcelL) that is a skill based, practice oriented, experiential, social learning programme developed initially to help International students become competent and effective in handling themselves in a new host culture. Recently, it is being extended to local university students in Australia, Canada, New Zealand and the United Kingdom as a tool for improving the cultural awareness and intercultural competence of local students.

From an institutional perspective, there are a number of well tested practices that can be considered elements of which have already been covered in reference to student and teacher perspectives such as:

- $\quad$ expansion of career services to provide International jobs for Domestic graduates as well as programme specific internships and practicum experiences

- $\quad$ organization of part-time work opportunities for International students to relieve some of the financial burden that many of them carry and provide valuable workplace experience in the host country to promote better interaction

- development of orientation programmes that are inclusive and incorporate a strong International dimension. International students need to be involved in the planning of such programmes

- development of elective courses that cover a wide range of issues related to globalization (business, health, social development, recreation, culture, etc.)

- development of cross border partnerships with other tertiary institutions that focus on staff and student exchanges

- development of close relationships with local multicultural groups and their involvement on councils, advisory committees and curriculum projects.

To date, no cookbook exists that provides us with all the answers that meet the following goals of Internationalization, such as strengthening the bonds of social interaction; enhancing classroom learning by building the expertise of teaching staff to manage increasingly diverse cohorts of students; designing curricula that are culturally inclusive and preparing graduates for expanded employment opportunities. Organization-wide strategic objectives are called for that systematically strengthen the Internationalization of curricula and document evidence of best practice in classroom management, teaching strategies that result in improved social interaction and help build community and an organizational culture of inclusion.

A generation has passed since large numbers of International students started migrating to Western tertiary institutions and much has been learned in that time. We have - albeit in a rather ad hoc manner - built up a base of knowledge and practice that should stand us in good stead for the future and takes us well beyond the thinking that little accommodation is required to fit International students (representing a lucrative revenue stream) into campus life. We still have a ways to go but, if the goodwill, flexibility and willingness to keep an open mind that has been evidenced by the participants in this study is to count for something, then there is room for optimism for the future. Hopefully, this study can stimulate further debate on how best to move to the next level in promoting intercultural harmony. This is the promise of evidence-based practice and research and continuing dialogue among organizations that have made a strategic and public commitment to become truly learner-centred in the broadest sense of the word. 


\section{REFERENCES}

1. $\quad$ Code of practice for the pastoral care of International students (revised December 2003). Retrieved November 11, 2004, from http://www.minedu.govt.nz_doc.cfm?layout_document-documented=6902\&ind.

2. EXCEL intercultural skills programme - train the trainers workshop. 2005. Retrieved September 29, 2005, from http://www.vuw.ac.nz/conted/courses/professional/excell.asp.

3. Gay, G. (2000). Culturally responsive teaching: Theory, research and practice. New York: Teachers College Press.

4. Ho, E., Holmes, P., \& Cooper, J. (2004). Review and evaluation of International literature on managing cultural diversity in the classroom. University of Waikato, Hamilton, New Zealand: Ministry of Education and Education New Zealand.

5. Knight, J. (1997). Internationalization of higher education: A conceptual framework. In Knight, J. and de Wit (Eds.), Internationalization of higher education in asia pacific countries. Amsterdam: EA/E/IDP.

6. Knight, J. (2000). Progress and promise. The 2000 aucc report on Internationalization at Canadian universities. Ottawa, Canada: Publication and Communications Division, Association of Universities and Colleges of Canada.

7. Knight, J. (2003). Updated Internationalization definition. International Higher Education, 33, 2-3.

8. Knight, J. (2004). Internationalization remodelled: definition, approaches, and rationales. Journal of Studies in International Education, 8 (1), 5-31.

9. Segal, P. (1994). As they see us and as we see them: American students view foreigners and foreign-born students view Americans. Migration World Magazine, 22, 2-3, 17.

10. Ward, C. (2004). The impact of International students on domestic students and host institutions. Wellington, New Zealand: Export Education Policy Project of the New Zealand Ministry of Education.

11. Wintec's mission, vision, values, and goals. 2005. Retrieved September 9, 2005, from http://www.wintec.ac.nz/index.asp?pageID=2145821737.

\section{About The Authors}

Dr. Ted Dunlop is a member of the Executive of Waikato Institute of Technology and Dean, Faculty of Health, Arts and Social Sciences. Dr. Dunlop has a broad background in International education from his work across four jurisdictions in Canada and most recently New Zealand.

Deniss Yeung is a Senior Lecturer in the School of Business and Administration, Faculty of Business and Technology, Waikato Institute of Technology. He is a Chartered Marketer (U.K.) with strong research interests in not for profit organizations and International student issues.

\section{NOTES}




\section{NOTES}

